\title{
AS THE WEST MAKES ROOM FOR THE BRICS WHAT ARE THE IMPLICATIONS FOR EMERGING BUSINESS MODELS?
}

\author{
DAVID WALTERS
}

\section{INTRODUCTION: THE BRICS AS EMERGING MARKETS: OPPORTUNITIES AND CHALLENGES}

The relative decline of the west is all too evident, but this is the victory of capitalism. Modern neoclassical growth theory suggests that with converging economic resources open capitalist economies should converge. Then, the most populous countries would become the leading economies. This is the importance of the BRIC economies. It is a very diverse grouping. Its unifying criteria are high economic growth, a certain economic backwardness and large size, while the Bric countries vary greatly in terms of economic development, economic structure, location, and interests. Brics has made sense for a decade as an investment theme, but will it for much longer? Russia matched China and India with a real annual average growth rate of seven per cent between 1999 and 2008, but its peculiarities stand out (Åslund, 2010).

\section{Brazil}

The Brazilian economy's solid performance during the financial crisis and its strong and early recovery, including 2010 growth of $7.5 \%$, have contributed to the country's transition from a regional to a global power and is expected to continue to grow. in the $4 \%$ to $5 \%$ range. The economy is the world's eighthlargest and is expected to rise to fifth within the next several years (Travel Document Systems, 2011).

It continues to be the largest recipient of foreign direct investment in Latin America; the United States is traditionally the top foreign investor in Brazil. Since domestic savings are not sufficient to sustain long-term high growth rates, Brazil must continue to attract off-shore investment, especially as the government plans to invest billions of dollars in off-shore oil, nuclear power, and other infrastructure sectors over the next few years. The major international athletic competitions that Brazil will host every year until the 2016 Rio Olympics are also leading the government to invest in roads, airports, sports facilities, and other areas and this will be an attraction to companies considering locating activities in Brazil (Travel Document Systems, 2011). 
U.S. Government, private sector, and academic researchers have extensive ties with Brazilian counterparts. Areas in which there is close cooperation include biofuels, medical research, remote sensing, and agriculture. The extent of bilateral scientific and technological cooperation is expanding and prospective areas in which to expand include advanced materials, telecommunications, energy transmission, and energy efficiency (Travel Document Systems, 2011).

Brazil has one of the most advanced industrial sectors in Latin America. Accounting for roughly one-third of the GDP, Brazil's diverse industries include automobiles and parts, machinery and equipment, textiles, shoes, cement, computers, aircraft, and consumer durables. Brazil continues to be a major world supplier of commodities and natural resources, with significant operations in lumber, iron ore, tin, other minerals, and petrochemicals. Brazil has a diverse and sophisticated services industry as well, including developed telecommunications, banking, energy, commerce, and computing sectors. The financial sector is secure and provides local firms with a wide range of financial products, yet interest rates remain among the highest in the world. The largest financial firms are Brazilian (and the two largest banks are government-owned), but U.S. and other foreign firms have an important share of the market (Travel Document Systems, 2011).

\section{Russia}

In economic development, Russia is superior to the other Brics. Russia has by far the highest GDP per capita, in 2008, it was $\$ 12,000$ in current US dollars, some four times that of China. Goldman Sachs forecasts that Russia will be the only Bric country to approach European per capita income levels by 2050. Russia's higher income level is also evident in superior social indicators. In most regards, Russia is slightly more advanced than Brazil but head and shoulders above China and India. More than two-thirds of Russians of university age are enrolled in university, compared with less than one-fifth of the Chinese. In terms of education, Russia matches the West. The differences with the Brics in consumption are also great. There are 14 times more cars in stock per capita in Russia than in China, and three times more computers. In many ways, Russia is already converging with the West. (Roland Nash, the chief investment strategist at Verno Capital), quoted by (Allen, 2011).

The Russian economy has undergone massive changes since the fall of the Soviet Empire, transitioning from a state controlled, socialist structure to a more market based, and globally integrated economy. Economic reforms in the 1990s privatized most industries, and some energy and defense related sectors. Russia's heavy reliance on commodity exports made the country vulnerable to the global economic crisis of 2008. The Russian economy has averaged 7\% growth since the 1998 crisis, resulting in the emergence of its middle class. Though the Russian economy was one of the hardest hit during the 2008-2009 crisis, the signs of recovery were evident in 2010. This has been due to the rising oil and commodity prices, and the government's $\$ 200$ billion rescue package to increase 
liquidity in the banking sector. Its GDP grew 3.966\% over 2009, making it the 87 th fastest growing economy in the world. This follows a near-catastrophic drop in 2009 GDP of $-7.90 \% .2011$ performance is expected to further improve, with the IMF forecasting 4.34\% growth to domestic product (Åslund, 2010).

\section{India, China and Asia}

Gordon Brown, former prime minister of the UK, considered the future reality of the-post GFC business environment. The collapse of trade in 2009, the large increases in unemployment and the consequent reduction in living standards requires an international financial and economic strategy (Brown, 2010).

Brown discussed the role of Asia in the coming years: China will soon overtake the USA as a manufacturer and this will be reflected in the investment in capabilities and capacity. He suggests that despite the current (2010/11) problems of low growth and high levels of unemployment both the US and Europe can play a major role in the next decade and beyond. Brown argues that the rapid, and massive, expansion in Asian manufacturing Asian producers will become new middle class consumers. Currently Chinese consumer spending is three per cent of world economic activity compared with the European and USA's 36 per cent. He suggests that by 2020 or so, Asia and the Emerging Markets will bring double America's consumer power to the world economy; he points to GE, Intel, Proctor and Gamble as having announced that the majority of their growth will occur or come from Asia.

Gordon Brown sees Asian consumer growth as "the exit strategy from our economic crisis". Business is now relatively well equipped to respond to this challenge; the functional "silos" have given way to a customer focused process approach with processes now developed well beyond the intra-organisational approach and are inter-organisational in their operations with many crossing international borders see (Fung et al, 2008). The strong growth is likely to continue in China and India (close to ten per cent) compared with very poor growth in Europe, Japan and the US of a little over two per cent!!! Winestock (2010) cites Stephen Walters (JP Morgan, Australia) who suggests the structural change in the global economy, particularly the rise of China and India, has further to run!! There are important implications here; Asia has become the manufacturing engine of much of the world and businesses in the rest of the world must now accommodate the changes this demands of them.

Gittings (2011) reminds us that in the $18^{\text {th }}$ century - before the West's industrial revolution - India and China together accounted for almost half of gross world product.' "'As China and India continue to develop, the growing cities now driving demand for Australia's mineral resources will be populated by an increasingly wealthy and upwardly mobile middle class, with incomes and tastes to match," "Increasing consumer purchasing power and changing spending patterns will open up new, often unforeseen, opportunities for Australia - well beyond those flowing from the current mining boom." Comment from Australian Federal Government Treasury cited by Gittings (2011). 
One study has estimated that the number of middle-class consumers in Asia could increase by more than 1.2 billion people by 2020 . If so, these projections would mean that by the end of this decade Asia would have more middle-class consumers than the rest of the world combined, with China surpassing the United States as the world's single largest middle-class market in terms of dollars. By 2030, with India following China's lead, the world could have gone from mostly poor to mostly middle class, with two-thirds of the world's middle-class consumers living in our region.

China is fast approaching income levels where consumption switches from necessities. The Chinese government is focused on reforms to foster higher growth in household incomes and to rebalance the economy towards domestic demand. The "Treasury" suggests considerable scope exists for a strong rise in the consumption ratio in the medium term. Urban households constitute a large and growing proportion of China's 400 million households (Australia has 8.5 million). Just over the past 10 years, the proportion of urban households owning a car has gone from virtually none to 12 per cent. The proportion owning microwave ovens has gone from 16 per cent to 58 per cent. But China is fast approaching income levels where consumption often turns, and the Chinese government is focused on reforms to foster higher growth in household incomes and to rebalance the economy towards domestic demand. So Treasury says there's considerable scope for a strong rise in the consumption ratio in the medium term.

Experience from countries such as Japan and South Korea suggests that as the amount of consumer spending grows its composition changes; they become more affluent; people devote a higher proportion of their spending to services and consumer durables. The early stages of such a shift are already evident in China. Since the early 1990s, its urban households have devoted a declining proportion of their spending to food and increasing proportions to medical services, transport and communication, and education, recreation and culture. Gittings op cit "Schumpeter" (2011), in the Economist, reviews the business models of the 'Emerging Markets'; noting that the 'BRICS' recovered from the 2008 financial crisis far quicker than the traditional Western companies and that many of them are leading the 'growth by acquisition' activity. The article reports on a study by BCG of some 100 BRIC companies they report revenues growing (on average) at 18 per cent per year (three times faster than non-financial companies in the S\&P 500. They have managed to expand fast without diluting their profit margins (which at 18 per cent were 6 per cent higher). BCG argue that these results are because they have managed to resolve the trade-offs usually associated with corporate growth between of volume against margin; rapid expansion against low leverage (debt), and growth against dividends. They have increased sales three times faster than traditional global operators and have reduced debt/equity ratios by some three-percentage points, and have achieved a higher dividend/share price ratio every year apart from one. There were exceptions: the pharmaceutical industry (that primarily focused on low margin generic drugs and the consumer 
durables manufacturers that focused on low-cost products, avoiding the high price segments). BCG suggests these could be exceptional performances in exceptional times as the BRIC competitors 'catch-up'.

\section{RESPONSES: WHAT ARE THE IMPLICATIONS FOR THE 'EMERGING WESTERN BUSINESS MODEL'?}

Iansiti and Levien (2004) made a significant comment some six years ago: "Strategy is becoming, to an increasing extent, the art of managing assets that one does not own". Arguing that business networks are ubiquitous in our economy they suggest the pervasive networked nature of our business environment has triggered a significant evolution in the design of business operations and in the role of managers. Business networks did not start with the Internet; their pervasiveness is the result of as evolution in social, economic, political and technological systems that have stretched over the last few centuries." The authors comment on the structure of the Italian apparel industry (Prato, Northern Italy) that has been a loosely structured network of a number of specialist provider organisations (often comprising one person) that responded successfully to intensive competition in the $1950 \mathrm{~s} / 60 \mathrm{~s}$ and that owed its existence to the structure that originated in Renaissance Italy in which an impannatore integrated and coordinated their activities. See (Piore \& Sabel, 1984) for a detailed account of this early network based business model.

\section{Globalisation: is not the Timeless Solution it was once thought to be}

Globalisation was an initial move into what were more resource markets (primarily sources of low cost labour) It is interesting to observe diverging business models as companies such as Ford Motor Company are developing further towards continuing with a move to global platforms that streamlined the way the company builds cars for markets worldwide and is one of the key cost restructuring initiatives that helped return the Dearborn-based automaker to profitability following the Global Financial Crisis. At an Ernst \& Young's Strategic Growth Forum on November 10, 2010, Executive Chairman Bill Ford, discussed his company's turnaround and other key auto industry and manufacturing issues. The company's move away from building cars uniquely for individual countries along with successful collaboration with its union leaders has brought costs down significantly and the company's latest Ford Explorer model is being built in Chicago and will be exported to 93 different countries. The plan is to continue to export from the U.S. to around the world pursuing a "One Ford" global design and development strategy with only small adjustments for local tastes. Figure 1 describes the global business model being used by Ford and other large international organisations. The new Ford Focus will be built on one platform and will have the same engine, transmission, chassis and main body in all markets where it is sold (Katz, 2010). Whirlpool acquired the home laundry assets of Philips NV recently to pursue a similar strategy. An important cost issue here is what the traditional cost models can continue to offer? However it is 
becoming increasingly arguable that globalisation is no a longer appropriate response. A recent article from Knowledge@Wharton (2011) cites comments from the Boston Consulting Group's Asian operations suggesting that large organisations are aware of a "two-speed world" and are adapting their business models to accommodate the changes. General Electric with its " $15 / 50$ " frugal innovation program (see below) is one of the most reported examples but other companies in other industries are also adapting to the challenges.

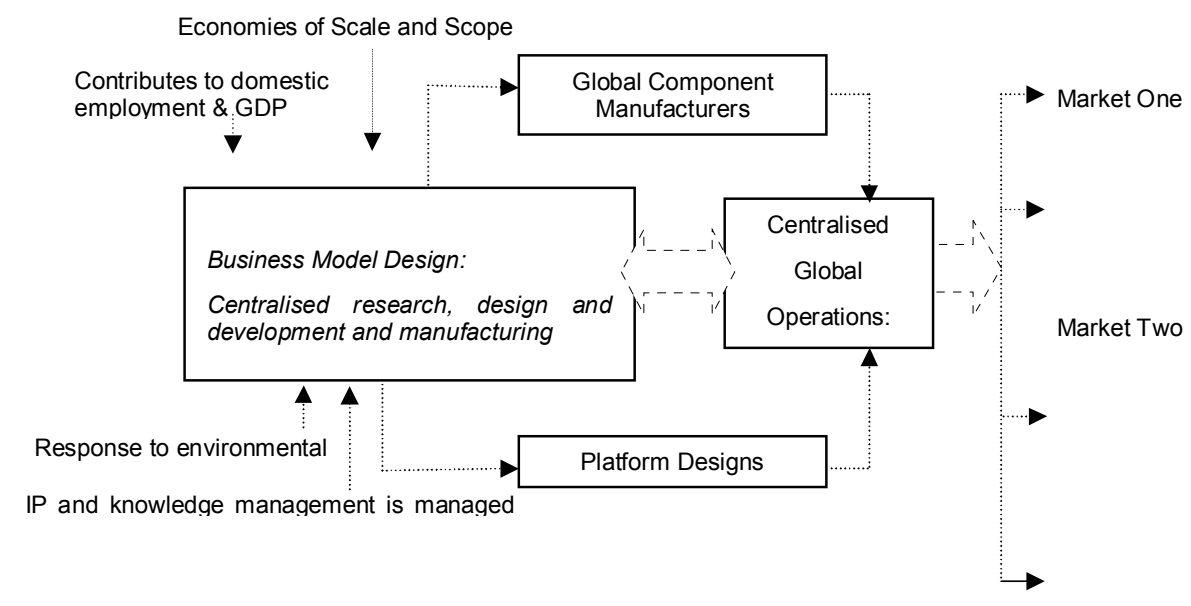

Figure 1-GLOBAL OPERATIONS Business model automobiles and consumer durables

\section{Networked Operations: Distributed Capitalism and Dispersed Manufacturing}

\section{The Factory of the Future}

Changing stakeholder expectations have clearly brought about changing patterns of corporate responses. In Europe and the Asia/Pacific regions the growing power of the emerging or newly developed economies has evoked positive responses. The Manufuture-European Technology Platform was launched in December 2004 from which emanated a recommendation for the preparation of a more detailed Strategic Research Agenda, identifying research priorities to be implemented. In the subsequent "Agenda" a number of concerns were expressed. The report identifies two major threats to European manufacturing. In the high value/low volume sectors the threat is emerging from developed countries; in the high volume/low value sectors the threat is from the industrialised Asian countries. However it is arguable that countries such as India and China now compete in both sectors.

Manufuture (2006) considered the changing characteristics of the marketplace suggesting the market increasingly demands products that are customised, yet available with short delivery times. The business focus must shift from designing 
and selling physical products to supplying a system of product-services that meet end-user demands while they also reduce total life-cycle costs and environmental impact. A fundamental concept of the Manufuture vision is one of "innovating production" which embraces new business models, new modes of "manufacturing engineering" and ability to profit from ground breaking manufacturing sciences and technologies. The report suggests a dominant business model that will emerge:

"The "virtual factory" of the future will manufacture in adaptable networks linking medium and large-sized OEMs with value chain partners and suppliers of factory equipment/services selected according to needs at a given time. Its composition will not be limited by the presumption of physical co-location or by a need to maintain long-term relationships."

(Manufuture-EU, 2006)

Table 1 -Characteristics of the emerging business models

\begin{tabular}{|l|l|}
\hline Traditional Approaches Was/Are & New Approaches Are/Becoming \\
\hline Command & Integration \\
Control & Coordination \\
Vertical/hierarchical structures & $\begin{array}{l}\text { Holistic/virtual structures - distributed } \\
\text { operations }\end{array}$ \\
Static processes: slow or nil responses & Dynamic processes: rapid responses to \\
to market or production process changes & value migration \\
Suboptimal productivity & Super-optimal productivity* \\
Reactive market responses & Proactive market responses \\
Inter-organisational competition & Inter-organisational collaboration \\
Generic and mass customised solutions & Customer specific product-service \\
& solutions \\
Lagged/limited content/expensive & Instantaneous/comprehensive content/low \\
system communications & cost communications \\
Restricted interactions & Comprehensive interactions \\
Entrepreneurship and Intrapreneurship & Interpreneurship* \\
\hline
\end{tabular}

Note:

Many of the concepts in Table one need no explanation but perhaps two (*) items do need explanation. Super-optimal productivity refers to the ability to couple processes such as design and development through ICT (information communications technologies) to increase productivity in a time space. The example given by (Friedman, 2004) (Bell and Lucent working a 24 hour shift across China, India and the US) is an example of super-optimal productivity. Interpreneurship identifies the business management skills that integrate and coordinate networks of organisations. 
In many situations the Manufuture prediction is more a confirmation that present trends will continue and the network based business model is becoming well established, as the examples above suggest. Table 1 identifies a number of changes that are currently influencing the emerging business model; of interest here is the response to value migration and to distributed operations. A characteristic of value migration is that it results in a repositioning of the production of 'market value'. This change often results in a restructuring of profit sharing throughout the business model. Uren (2001) quoted Schremp (CEO, Daimler Chrysler) who expressed the view: “......within 10 years the price of a car will represent only a quarter of the total value provided to a customer with the balance consumed in maintenance, finance and other services".

Barkai and Manenti (2011), suggest current market trends require the future production environment to be highly adaptable and reconfigurable to respond to rapid changes in market demand, technology innovation and changing regulations. Flexible manufacturing technologies employed by most automakers are a critical ability in this process and the foundation for profitable growth, but these alone will not suffice in a long term strategy to fend off the competition. The authors suggest a practical "design anywhere, make anywhere, sell anywhere" strategy is needed, and propose, arguing that:

"Factories of the future will be a global network of production facilities managed as single virtual factory. This type of manufacturing network consolidates multiple resources and capabilities to form an end-to-end fulfilment network that we call fulfilment execution system (FES)."

FES is an approach to a coordinated management of demand, capacity and resources, and outbound order fulfilment across the entire network of manufacturing plants and along the supply chain. The authors' proposal relates to the regional-consolidation model; data gathered will be connected to corporatelevel intelligent decision support tools, creating visibility and intelligence on operational data. It enables manufacturers identify problems, isolate root causes, understand the state of execution processes, and adopt corrective actions quickly across multiple plants. The authors' proposal takes us beyond the marketspace/marketplace work by Rayport and Sviokla (1994) in which they suggested the traditional marketplace interaction between physical seller and physical buyer are being eliminated. Zuboff (2010) argues that for many goods and services, new business frameworks are emerging: federations of enterprises - from a variety of sectors - that share collaborative values and goals are increasingly capable of distributing valued assets directly to individuals, enabling them to determine exactly what they will consume, as well as when and how. This shift not only changes the basis of competition for companies but also blurs - and even removes - the boundaries between entire industries, along with those that have existed between producers and consumers. See Figure 2. 


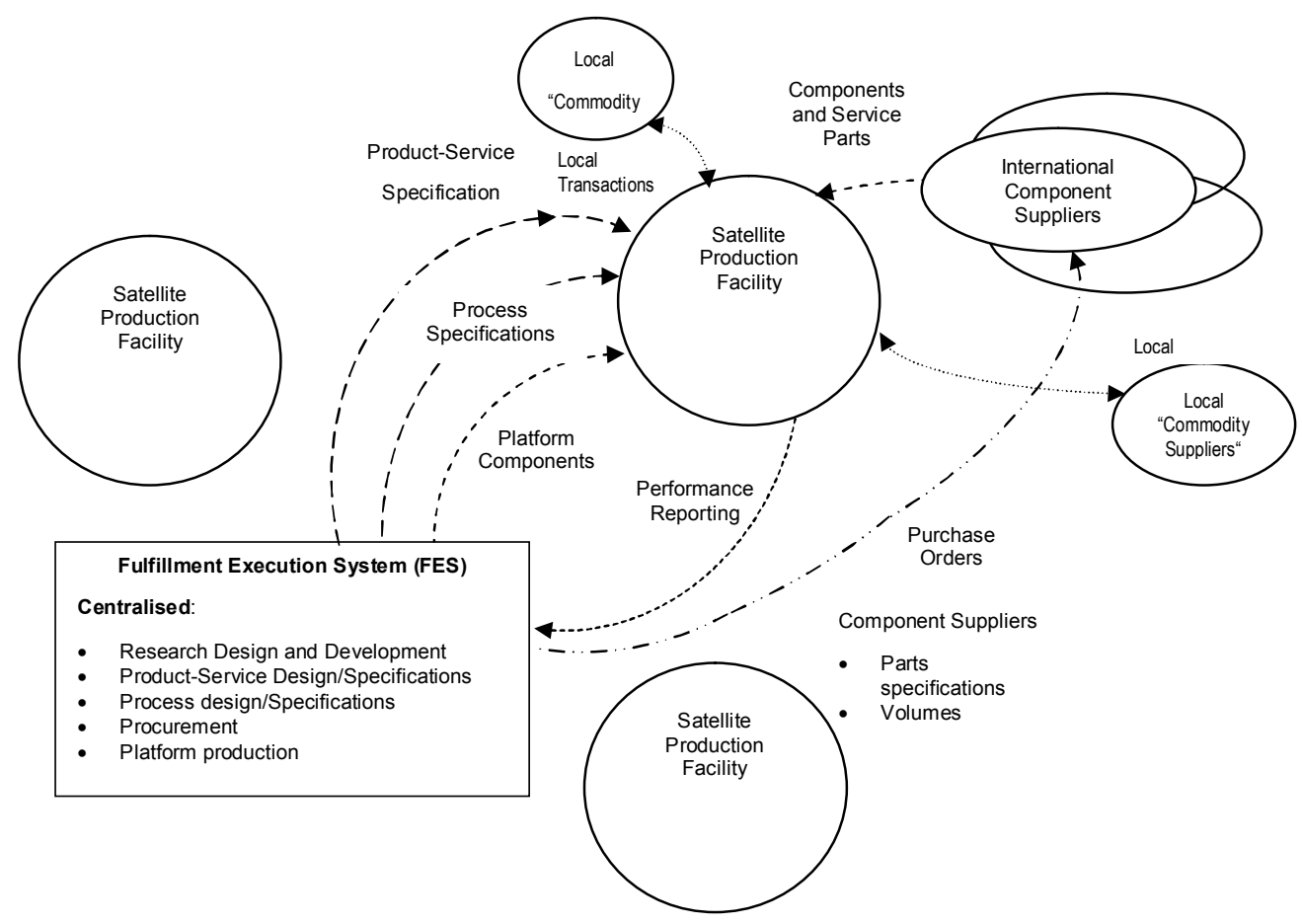

Figure 2 - An example of a "Factory of the Future"

\section{Additive Manufacturing: "Individualisation is becoming a Reality}

The Economist (2011) explored the world of the fabricator, the application of 3D printing technology to manufacturing. Designers and Engineers have been using 3D printers for more than ten years; initially to produce prototypes rapidly and at low cost. Currently they are now capable of using a wider range of materials (plastics and metals) and their accuracy is been developed such that it is estimated that more than 20 per cent of the output from 3D printers is now final products and this estimated to have increase to 50 per cent by 2020 .

It is likely that Additive Manufacturing will have a major impact in the value chain network by lowering both fixed and variable costs. The equipment (the fabricator) now costs less than a laser printer did in 1985, it is compact and does not require anywhere near the production facilities currently in use producing similar products. Savings in variable costs are realised by the savings in raw materials, where it is estimated $3 \mathrm{D}$ printing uses some 10 per cent of input materials.

The Economist argues that: "The industrial revolution of the 18th century made possible the mass production of goods, thereby creating economies of scale which changed the economy - and - society - in ways that nobody could have imagined at the time. Now a new manufacturing technology has emerged which does the opposite". In the mid-1990s mass-customisation was offering 
considerable competitive advantages; now customisation offers the potential of not just exclusiveness but of uniqueness. The Economist suggests potential for focusing RD\&D in central locations that is linked by ICT to the market place, thereby expanding the notions of Rayport and Sviokla and those of Zuboff.

\section{Dispersed Manufacturing or Distributed Assets}

Friedman (2005) discussed the impact of 'technology' on the generic business model. He identified three stages of development towards globalisation. Stage one occurred during the period between Columbus's discovery of the New World and the development of global trade using the transportation technology and rudimentary relationships management of the $15^{\text {th }}$ century. Stage two occurred from 1800 to 2000, when transportation and communications increased in efficiency with significant reductions in costs, and the factory and mass production began to offer products that were affordable to almost everyone. Stage three arrived when the PC and the Internet were established as the conduit that connected people and work units to each other wherever they were located instantly at low cost and with a high level of accuracy using what Friedman labelled as workflow software; the result of stage three is that individuals (and organisations) are able to contribute to the production of a product-service project from any location anywhere in the world; this has led to the development of holistic approaches to operations often referred to as distributed assets and/or dispersed manufacturing.

An example of a distributed asset/dispersed manufacturing business model is $\mathrm{Li}$ and Fung, a Hong Kong based value chain network coordinator working with some $10000+$ partner organizations in 40 countries, manufacturing a range of apparel products from high quality woollen sweaters to synthetic slacks: Li and Fung sit at the hub of a network of specialist enterprises that mobilize resources in different combinations depending upon the rapidly changing demand and coordinate a response. Li and Fung have undertaken an interpreneurial role by integrating and coordinating the productive capacity of these organisations. The aerospace industry shares a similar structure; Boeing Aircraft uses some 900 suppliers based in seventeen countries worldwide in the construction of the 777 aircraft (Boeing, 2011). The number of suppliers for the 787 is reportedly higher and has been responsible for much of the delay in deliveries; Boeing also changed their partnership agreement terms expecting them to undertake much of the R\&D tasks - this has not materialised.

Another model finding support is the original-design manufacturer (ODM), a model that is based upon product innovation. Taiwan's Compal and Quanta Computer, offer equally compelling examples of distributed product innovation. These ODMs creatively pull together highly specialized component and subsystem suppliers in order to generate ideas for delivering higher performance at lower cost in a broad range of digital devices, including digital still cameras, mobile telephones, and notebook computers. Instead of designing products in detail from the top down, ODMs specify ambitious performance targets and then 
rely on this diverse network of technology partners to find new ways of meeting them. It has been suggested that the recently introduced iPhone by Apple follows this principle. In each of these examples we see business models that are designed to create value innovation in extended product-service markets.

\section{Distributed Capitalism: "A Market of One"}

Zuboff (2010) discusses the progressive role of the business model evolution in "creating value in the age of distributed capitalism" by introducing the notion of mutations. Zuboff argues that the leading edge of consumption is now moving from products and services - to tools and relationships enabled by interactive technologies. Amazon.com, Apple, eBay, and YouTube being familiar examples, and identifies lesser-known companies like Cell Bazaar in Bangladesh (in emerging-market mobile commerce in rural locations), TutorVista (in tutoring), and Livemocha (in language education). While innovations improve the framework in which enterprises produce and deliver goods and services; mutations create new frameworks; they are not simply new technologies, though they do leverage technologies to do new things. Historically, mutations have superseded innovations when fundamental shifts in what people want require a new approach to enterprise: new purposes, new methods, and new outcomes. In the way that mass production moved the locus of industry from small workshops to huge factories, today's mutations have the potential to shift us away from business models based on economies of scale, asset intensification, concentration, and central control. Zuboff argues that for many goods and services, new business frameworks are emerging: federations (value chain networks) of enterprises - from a variety of sectors - that share collaborative values and goals are increasingly capable of distributing valued assets directly to individuals, enabling them to determine exactly what they will consume, as well as when and how. This shift not only changes the basis of competition for companies but also blurs - and even removes - the boundaries between entire industries, along with those that have existed between producers and consumers.

Zuboff's argument is that the technology of mass customisation and of product platforms provides a means of 'offering most of the market, most of what it wants'; in other words the concept of "dispersed manufacturing" as practiced by Li and Fung (Fung et al, 2010) supports mass customisation. Zuboff's mutations concept creates business model structures that permit and indeed require customer participation (co-creativity) in the production of more closely individualised product-services. This suggests that network business model design is becoming process innovation led. Distributed capitalism takes the technologies associated with the Internet, mobile computing, wireless broadband and related developments in digitization and software applications and creates a convergence of technological capabilities and the values associated with the product-services required for individual self-determination.

The Economist (2010) identifies three 'general lessons'; the Silicon valley type cluster is not essential to succeed; a focus on traditional strengths in established 
industries appears to be sufficient, A second point is that niche markets can aggregate into large global activities; given the success of GE and Toshiba (below) this is a valid claim. And third; sustained focus on capabilities with innovative products and processes does have rewards. Product and process innovation is emerging as an important issue.

There are other factors - the economics of production, taxation policies and exchange rates are seen as important. The Economist reports activities by a number of Japanese organisations to move production off-shore: "Japanese firms do $30 \%$ of their manufacturing overseas - twice as much as in the early $1990 \mathrm{~s}$. Toshiba's foreign-made share has grown from $52 \%$ to $56 \%$ in the past year alone. Fuji Xerox and Yamaha Motor boast levels of $80 \%$ and $94 \%$ respectively. As the yen hits 15-year highs on a nominal basis, there is more pressure to ship operations abroad". The report suggests longer-term factors besides the yen's recent strength. One is productivity. Overseas subsidiaries have profit margins about one-third higher than those of domestic operations, according to the trade ministry. A second is proximity to consumers in fast-growing economies. In 2001 only $40 \%$ of Japanese companies' overseas production in Asia went to local consumers. Now the proportion is $62 \%$ and growing. The third is tax. Japan's effective corporate tax rate, at $41 \%$, is the highest among G20 countries, and almost twice that of South Korea. Many carmakers have moved production to Thailand not only for low taxes but also because of that country's free-trade agreements (FTAs), which let them export across the region free of tariffs. A fourth is the differential in exchange rates that can be punitive for organisations manufacturing in 'high value' countries and selling their products in countries with deflated exchange values. Nissan announced they intended to increase offshore manufacturing due to the increasing strength of the Yen and its impact on prices in overseas markets. (IndustryWeek/Agence France-Press: 2010)

The Economist report adds: "Losing factories in Japan is particularly pernicious because much of the country's advantage lies not in design but in processproducing at large scale and with a low defect rate. Companies still keep "mother factories" in Japan to refine their production processes and retain skills. But their foreign plants need this mothering less than they used to: three-quarters of Japanese-owned foreign plants were at the same technical level as domestic ones in 2008, up from about half in 1996."

An example of a distributed asset/dispersed manufacturing business model is $\mathrm{Li}$ and Fung, a Hong Kong based value chain network coordinator working with some $10000+$ partner organizations in 40 countries, manufacturing a range of apparel products from high quality woollen sweaters to synthetic slacks: $\mathrm{Li}$ and Fung sit at the hub of a network of specialist enterprises that mobilize resources in different combinations depending upon the rapidly changing demand and coordinate a response. Li and Fung have undertaken an interpreneurial role by integrating and coordinating the productive capacity of these organisations. The aerospace industry shares a similar structure; Boeing Aircraft uses some 900 suppliers based in seventeen countries worldwide in the construction of the 777 
aircraft. (Boeing, 2011). The number of suppliers for the 787 is reportedly higher and has been responsible for much of the delay in deliveries; Boeing also changed their partnership agreement terms expecting them to undertake much of the R\&D tasks - this has not materialised.

Another model finding support is the original-design manufacturer (ODM), a model that is based upon product innovation. Taiwan's Compal and Quanta Computer, offer equally compelling examples of distributed product innovation. These ODMs creatively pull together highly specialized component and subsystem suppliers in order to generate ideas for delivering higher performance at lower cost in a broad range of digital devices, including digital still cameras, mobile telephones, and notebook computers. Instead of designing products in detail from the top down, ODMs specify ambitious performance targets and then rely on this diverse network of technology partners to find new ways of meeting them. It has been suggested that the recently introduced iPhone by Apple follows this principle. In each of these examples we see business models that are designed to create value innovation in extended product-service markets.

\section{RESPONSES TO NEW COMPETITORS, NEW "RULES" AND SHRINKING TIME HORIZONS}

An indication of how "new rules" are appearing in the new economy markets is indicated by a recent edict by the Chinese government. China is debating a 10year plan that sets rules on how foreign auto makers transfer key technologies to China if they opt to produce and market EV cars and plug-in hybrids there. It is reported that Beijing is considering a 10-year plan that aims to set rules and regulations on how foreign auto makers transfer key technologies to China if they opt to produce and market electric cars and plug-in hybrids there. A draft of the plan suggests Beijing could compel foreign automakers that want to produce electric vehicles in China to share critical know-how by requiring them to enter joint ventures with Chinese firms, some executives say. It also limits foreign firms to minority stakes in any alliances that are created (www.industryweek.com, 2010).

To achieve sustainable competitive advantage in the New Economy requires 'an innovative business model requiring considerable investment'; even this does not necessarily guarantee success, rather it puts the firm in the 'qualifying category'. As the business environment becomes increasingly influenced by global events and sustainability priorities there is no guarantee that the innovative productservice, delivered by an innovative set of processes supported by unique/exclusive capabilities will succeed in a very competitive global market. Serial competitive advantage, offering an order winning value proposition has time constraints. The notion of 'value migration' having impact through new business models offering more cost-efficient value delivery to customers, or reducing the purchase price for the same purchase value is a constant threat. Serial competitive advantage seeks to extend the time horizon by creating 
collaborative networks with target market segments in mind; network structures can be organised to ensure that 'incremental differentiation' can be incorporated into the value proposition. Many organisations accept 'order qualifying' status and competitive necessity (rather than work for 'order winning' status and competitive advantage): their value proposition offering no advantages over and above competitive offers. An organisation offering obsolescent, perhaps obsolete product-services and processes is clearly at a competitive disadvantage.

\section{Globalisation versus Regionalisation}

If the "eighties and the nineties" was a period of globalisation; the "noughties" was one of moving towards regionalisation. There is an interesting difference of philosophy. During the "noughties" large international organisations realised that their investment in the emerging markets created consumer wealth and an increase in disposable incomes, so much so that the 'providers of low-cost labour' became consumers of their labours. Initially low labour costs and economies of scale (due to product range management) had strong incentives but the expansion of the domestic markets in these locations increased the attractiveness. As we have seen in recent months (January/June 2011) automobile sales in China are breaking growth records.

\section{Regionalisation: Approaches}

Regionalisation is increasing. It is becoming clear to a number of organisations that re-engineering products to reduce costs is not as effective as redesigning them to meet local requirements and to be manufactured locally to create goodwill and to take advantage of reductions in costs. General Electric (Healthcare) is practising reverse innovation, best described as:

“Offering a 'fifty percent performance solution' at fifteen percent of the cost of the one hundred percent solution" (Immelt \& Govindarajan, 2009).

Because:

- Local market needs in these markets is less sophisticated

- Local manufacturing resources exist but are also less sophisticated

- Local distribution and service support resources exist and can be used

- 'Reverse technology transfer': capabilities and processes to move the innovation into suitable markets in rich countries is more effective than attempting to modify and manufacture products for these markets in domestic locations.

GE introduced reverse innovation because it found that the traditional approach of developing sophisticated products in domestic markets and simplifying them for emerging markets was not effective primarily because of declining growth 
rates in developed markets and innovative competitors in the emerging markets. GE introduced a business model based upon five principles:

As a result LGTs were established in India and China. The following management model was created in order that:

- Relevant product-service strategy is developed by the LGTs (Local Growth Teams) by localising/shifting decision making to sourcing/consumption markets;

- Local circumstances are reflected in planning processes by understanding opportunities and constraints;

- LGT structures reflect local realities;

- Objectives and strategies become 'customised' to meet local (realistic) possibilities and constraints:

- An awareness and applications of product-service attributes relate to;

- Current local product-market practices;

- Relevant levels of complexity of local product and processes;

- Manage any conflict with the 'Corporate' global business;

- Manage resource requirements and allocation by connecting LGT with global R\&D and capital sources.

- Manage the transfer of the innovation into 'rich countries' developed markets.

It is interesting to note that these "basic" products are beginning to have markets in traditional markets.

Panasonic's EM-WIN program operates in 'BRIC", and other emerging markets (Brazil, Russia, India, China, Vietnam, Mexico, Indonesia, Turkey, and the Balkans). It estimated that sales to EM- Win markets will exceed sales to North America and Europe. EM-WIN has been a major activity for Panasonic over two years (2007/9). Panasonic undertook 'Lifestyle research' in order to redesign products to meet local requirements - reduced features and reduced manufacturing costs. By reducing features and localising design and manufacturing, costs can be reduced to reach acceptable prices: pricing targets are television \$US50, air conditioners \$US100, washing machines \$US200. Eliminating features simplifies the manufacturing processes \& requires fewer parts and permits the introduction of standard parts and platforms. Local production and contract manufacturing contains costs. It requires the re-design of products and processes in order to reach realistic cost levels. Japanese designs cannot be extended to EM-WIN; currently this is repurposed design and innovation caused by product life cycle shrinkage. Panasonic will need to 
perform a complete overhaul of how it conceives, designs \& manufactures its products. Panasonic expects EM-Win to increase sales of consumer products by almost 20 per cent. (Wakabayashi, 2009). By contrast Apple designs its products in the US and manufactures them in Asia; this is a viable strategy as the products are standard wherever they are sold. Clearly the economies of scale adequately compensates for the additional logistics costs involved. (Knowledge@Wharton, 2011).

Toyota has indicated its preference for regional activities; it will invest nearly $\$ 700$ million in its first fully-fledged research and development base in China in a bid to expand its share of the world's largest auto market. Toyota Motor Engineering \& Manufacturing (China) Co. Ltd will build the plant at an economic development zone in Changzhou, near Shanghai, with plans to begin operations in the spring of 2011. The new company will survey the Chinese auto market, study quality control at its local assembly plants and develop lowemission vehicles and engines for the local market. The company plans to raise the number of employees from an initial 200 to 1,000 . "TMEC ... aims to tailor vehicles to the demands of Chinese consumers" (Agence-France, 2010a).

Regionalisation offers an opportunity to identify, and accommodate, local customs and culture, local governance regulations (pharmaceuticals), patent laws, packaging requirements, and, distribution processes and practices. Regionalisation has taken international organisations well beyond identifying and using low labour costs but has introduced a requirement to understand all of the costs that are involved, such as logistics, quality control and the costs of failing to meet time demands of customers - that can result in lost sales and reduced margins.

An interesting dimension to globalisation versus regionalisation strategy was added by Nissan chief executive Carlos Ghosn who announced the Company's intention to move production and support functions to dollar-linked economies, including the United States and China, to avoid currency volatility; the company wants to correct a "big imbalance" in its costs and revenues due to making cars in Japan that are then sold in the United States and dollar-linked economies in Asia and to shift more of our cost from a yen base to a dollar base. Ghosn's remarks come amid fears that tensions over global trade imbalances could degenerate into a series of beggar-thy-neighbour devaluations as countries seek to gain a trade advantage from a cheaper currency. Ghosn told the Financial Times (2010) that exchange rate volatility of any kind was damaging to business because it undercut long-term strategy. "The only way you can protect yourself is by making sure your currency footprint is balanced. If there is any imbalance, it should be small".

Renault-Nissan is developing an alliance in Russia, where it has been invited to raise its stake in Avtovaz, the manufacturer of the Lada, to up to $50 \%$. Renault currently owns $25 \%$ plus one share of the struggling Russian automaker. Asked if he would accept Putin's invitation, Ghosn's reply indicated that Renault are 
going to put in a lot of technology, develop a lot of capacity, do a lot of things together between Avtovaz Lada, Renault and Nissan.

Unilever is reported to be very successful with a regional approach in India where they have replaced conventional marketing expenditures with consumer education and distribution spends, they found the population was not familiar with bottles containing consumer products and they have established a marketing channel based upon stores run by women in local villages as a response to the "informal economy" that persists with a large number of small roadside shops. (Knowledge@Wharton, 2011). Figure 3 identifies a typical regionalised corporate business model.

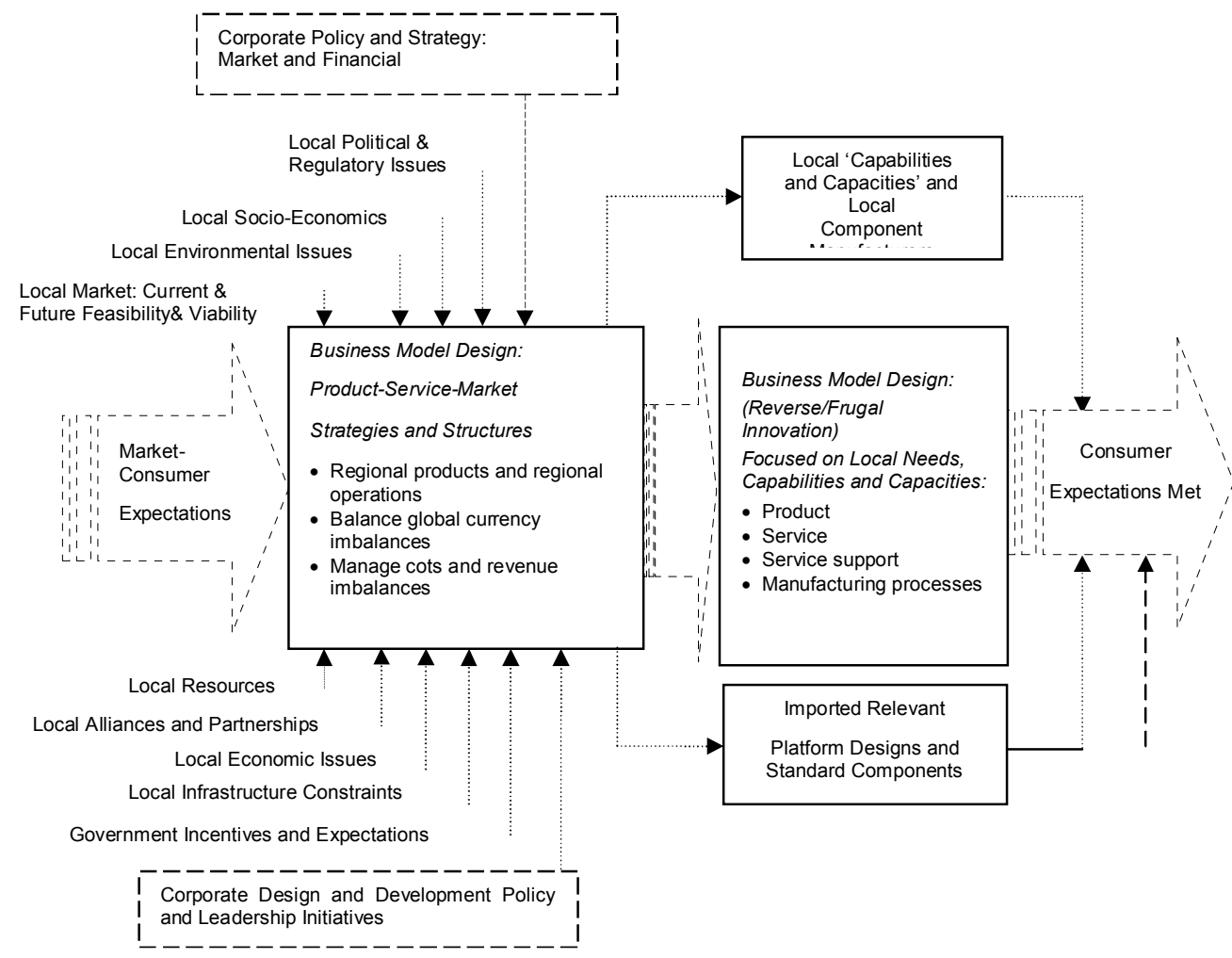

Figure 3 - REGIONAL OPERATIONS business model automobiles and consumer durables

\section{Collaborative Networks}

Some companies are learning how to take a more creative approach to mobilizing resources. Grey (2006), discusses collaboration from a resource management perspective; arguing that rigid resource based systems, typically highly automated factories operating with rigid and standardised processes that apply resources to specific places at predetermined times, are becoming obsolete. See Figure 4 Grey's argument is that resource mobilisation (the increasing externalisation of tasks and a corresponding increase in cooperative arrangements 
or networking.) is; "a necessary response to fragmenting less predictable demand. The Bishops Technology Group (Grey's company) collaborates with partners across the world to develop new innovative products. Grey suggests that an important facet of this activity is the relative ease with which information that flows between ODMs, suppliers, logistics providers, distributors, wholesalers and retailers can be captured providing giving valuable input about the efficacy of product design, and distributor and customer response. This suggests a major difference between rigid resource systems and mobilised resource systems. Rigid resource systems are the traditional manufacturing model in which production is based on sales forecasts and products when finished are moved into a finished goods inventory that is awaiting sale - it is what has become to be known as the push approach.

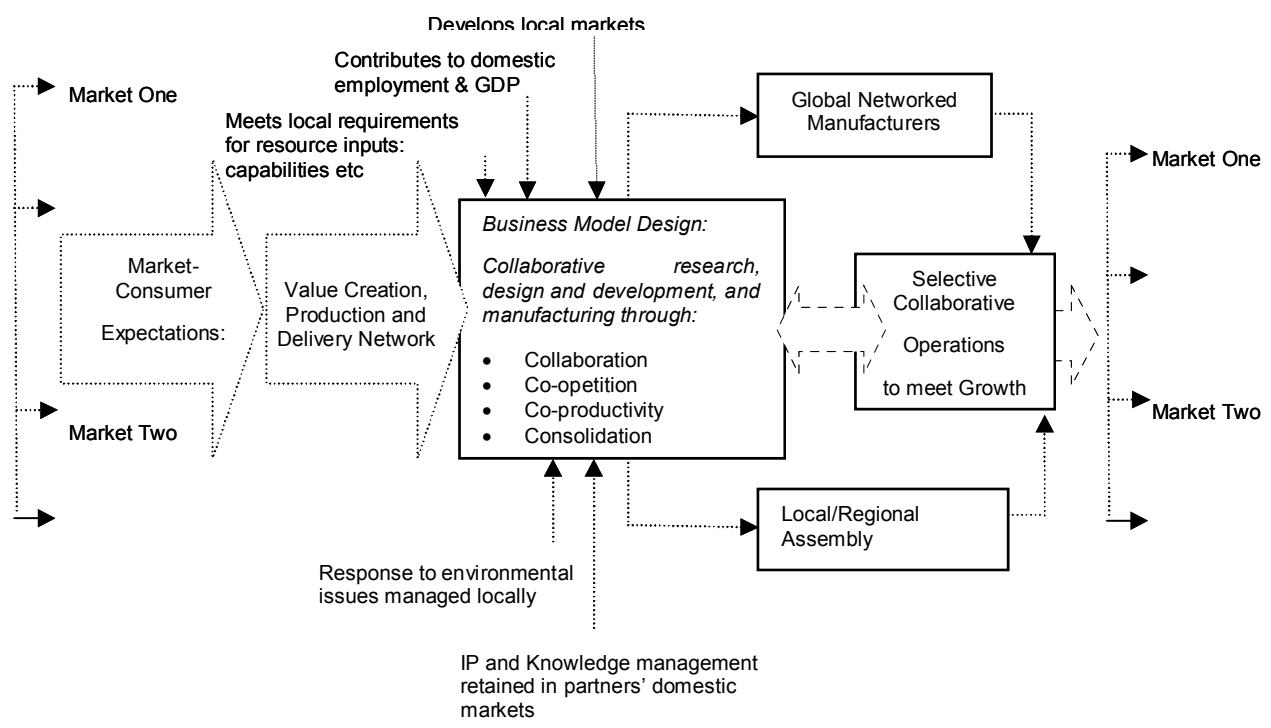

Figure 4-COLLABORATIVE NETWORKS Consumer and Consumer

Mobilised systems use demand chain analysis to identify opportunities and then identify the resource base required to compete successfully, and, in doing so expand (or contract) the resources network. This extends to the end-user customers who become co-creators by participating in the design process. This approach does not infer that the final output of the mobilised resources model is a highly customised, unique product; it is suggesting that customer satisfaction can be more closely achieved by using product and process platforms as modular systems that can be combined in a number of ways to meet end-user demand. Examples of product platforms are seen in the automotive industry where platform components are shared on an intra- and inter-organisational base - the pull approach. Examples of process platforms are seen in Internet merchandisers such as Amazon and e-Bay. 


\section{ORGANISATIONAL CONSIDERATIONS OF GLOBALISATION, AND REGIONALISATION}

The growth of globalisation and now regionalisation have extended the boundaries of the organisation to include nationally and internationally based partners. In addition to the changing attitude to strategy, structure and location, the move towards organisations as being partners within networks, operating as providers of specialist product-services within specialist markets is significant.

\section{A Role for SME's}

There are examples of SME organisations competing in the role of specialist providers. In Germany the term Mittelstand is sometimes applied to quite small, parochial firms, the most interesting ones are rather bigger and more outwardlooking. Most (some $90 \%$ of them) operate in the business-to-business market and $70 \%$ are based in the countryside (Economist, 2010). They focus on market niches, typically in areas such as mechanical engineering. Dorma makes doors and all things door-related. Tente specialises in castors for hospital beds. Rational makes ovens for professional kitchens. This strategy helps them avoid head-tohead competition with global giants. It has helped them excel in these market niches. Mittelstand companies dominate the global market in an astonishing range of areas: printing presses (Koenig \& Bauer), licence plates (Utsch), snuff (Pöschl), shaving brushes (Mühle), flycatchers (Aeroxon), industrial chains (RUD) and high-pressure cleaners (Kärcher). Globalisation has been a godsend to these companies: they have spent the past 30 years of liberalisation working quietly to turn their domination of German market niches into domination of global ones.

Japan also has a number of very successful medium sized organisations - chuken kigyo - strong medium sized firms that have a number of these organisations: Shamano, $60 / 70 \%$ of world's bicycle gears and brakes: YKK, $50 \%$ of world's zip fasteners: Nidec, $75 \%$ of world's motors for hard disk drives in computers: Mabuchi, $90 \%$ of world's micro-motors used to power the adjustment of rear view mirrors in automobiles: TEL, $80 \%$ of the etchers used in LCD panels: Covalent, $60 \%$ of containers that hold silicon wafers as they are converted into computer chips: Murata, $40 \%$ of world's capacitor market (50\% margin): Japan Steel Works, $100 \%$ of the world market for solid steel containers that contain radioactive materials. Globalisation has been a godsend to these companies: they have spent the past 30 years of liberalisation working quietly to turn their domination of German market niches into domination of global ones. Critics argue that emerging market companies (China, India, Brazil, etc) will eventually develop similar capabilities and need not depend upon the Mittelstand model. Further it is argues that they are too conservative. Counterarguments suggest that the Mittelstand model is robust; typically each organisation has a creditable number of overseas subsidiaries; these offer service and technical advice, may deriving their profitability this way. The article cites Hako as generating only 20 per cent of its revenue from the sales of equipment. However it is noted that 
Germany has a poor record in nurturing small organisations into major, world, organisations.

\section{The Value Chain Network as an Emerging Business Model}

It is certain that the "New Economy", whatever format that it eventually takes, will be influenced by this business model format and it is noticeable that in those countries where manufacturing rapidly migrated to Asia as it became industrialised (to the extent that it now dominates a number of sectors) there are signs (such as those suggested by the Mittelstand model) that being part of a value chain network can reduce the exposure to high volume/low value competition and that profitable opportunities do exist. The Economist article identified three 'general lessons': the Silicon valley type cluster is not essential to succeed; a focus on traditional strengths in established industries appears to be sufficient, A second point is that niche markets can integrate into large global activities. And third; sustained focus on capabilities with innovative products and processes has rewards. It can be argued that by identifying a specific customer 'solution' corporate size and distance are becoming irrelevant. Indeed if this is a core 'need', one shared by most members of an industry it is very likely that economies of scale will return in importance.

This may be more difficult than it would appear. Majocchi et al (2010), offer an interesting view of current issues and future prospects. In a presentation in New York (10 October 2010) the "Challenges of global manufacturing: improving North American and European competitiveness through cooperation", they identified a number of issues. There is reluctance among NA manufacturers to pursue global growth opportunities particularly in the emerging BRIC economies where dramatic growth is expected as "hundreds of millions" of consumers continue to expend. However this growth may well not be matched by manufacturing capacity. The authors comment on a survey by HSM Americas Inc, suggesting that while European manufacturers have learned how to serve the diverse needs of customers spread across the globe and have developed the know-how to cooperate with other companies in vertically-integrated value chains, North American manufacturing companies, especially small and medium sized enterprises, have not responded similarly and need to refine production capabilities for mass customisation in order to explore the potential overseas. This includes taking advantage of green technologies - before regulations require it - which can help establish a competitive advantage in the global marketplace. These comments suggest that very few organisations in North America would embrace the future predicted by Zuboff.

Some major differences between European and North American organisations were found. European manufacturers expressed a greater interest in increasing their production flexibility to attract business than their North American counterparts, who were more focused on reducing labour costs in the last two years, to offset economic challenges. In addition, fewer North American manufacturers were investing in innovation or R\&D than the Europeans. And 
green manufacturing initiatives, which can help drive down material costs and spur needed innovation, were embraced in greater numbers in Europe than in North America. The authors suggest some guidelines to initiate a move towards both effectiveness and efficiency: strengthen mass customization capabilities, leverage the power of partnerships, and, take a chance and learn about export opportunities. They concluded by commenting that it is a difficult transition, requiring cultural and structural change, adding that waiting is not an option, given the fact that competitors in China, India, Brazil and other emerging economies are moving fast to fill the void.

However, these comments do not necessarily apply to a significant number of "aware" North American manufacturers. Papers at the IMS (Intelligent Manufacturing Systems) Vision Forum 2006 made similar suggestions concerning future activities. Jason Myers (2006), Canadian Manufacturers \& Exporters, Canada, identified four 'agents of change' for Next Generation Manufacturing: customised solutions, a lean approach, 'the competitive batch of one", and, "managing time".

Myers suggested that manufacturing responses are already operating in the context of value chains that compete against each other; suggesting further that the extended businesses of the future will be virtual enterprises in which business units continuously reconfigure their operations, collaborative partnerships, and supply chain relationships, forming and reforming value chain networks on a project by project basis, relying upon value chain networked information systems and virtual engineering to ensure concurrent design, production, marketing, service and sales support. They will operate as if their firms are members of a single and flexible enterprise. There can be little doubt concerning the impact of these developments on all operations processes, particularly manufacturing and sales, and logistics and supply chain management processes.

Some examples of Australian companies that are responding to the need to work as a component of an international value chain network includes:

GKN Aerospace \& Engineering; has designed more than 1000 parts for the Lockheed-Martin F-35 Lightning 11 Joint Strike Fighter

Peregrine Australia; manufactures a radio frequency sapphire water chip combining antenna and amplifier for 'top-end 'mobile phones.

GPC Electronics, Sydney; Superior quality of systems and management (flexibility and complexity) has resulted in negotiated supplier lead times of 2 weeks and order response times for customers of 4 weeks.

Bosch Melbourne; R\&D led customised manufacturing that requires extensive knowledge IP inputs provides customers with market exclusivity/differentiation without extensive R\&D expenditure 
Codan communications equipment supplier, Adelaide; products based on standard modules reduces inventory holding and order lead times providing a 5/10 day order response time in comparison with competitors' 4 weeks or more.

GPC Electronics, Sydney; superior quality of systems and management (flexibility and complexity) has resulted in negotiated supplier lead times of 2 weeks and order response times for customers of 4 weeks.

International examples of collaborative strategies are also available and include:

Endo Pharmaceuticals/UPS (Healthcare Division): After acquiring DuPont's drug division positioned itself in the VCN to distribute prescription and other drugs in the US from contract manufacturers in overseas locations. Endo has a partnership in which leases space and UPS's expertise at handling controlled substances

Lego launched a "Classroom of the Future" project with US university to teach children about science \& technology; launched "LegoFactory.com" a "Lego Digital Designer" that offers an opportunity to design and order a unique Lego model, and; a joint venture with the MIT Media Lab that introduces robotic Lego

Dow Chemical: locates manufacturing close to the cheapest sources of energy (Middle East \& Russia) and from where it can contain the supply chain costs in servicing 'booming' markets in Asia and China

Philips: team up with academic \& industry with comparable research interests and capabilities to work on industry standardisation and technology developments

TomTom (GPS): identified its capabilities to be in 'innovating' in a particular area of technology and its understanding of consumer needs in the area. It established a manufacturing outsourcing capability rather than a manufacturing expertise

Hewlett-Packard: Outsources 90 percent of its manufacturing volume to some 40 suppliers. HP's core capability is now focused on 'managing contract manufacturing

UPS Inc: provides resources that enables both small (and some large) organisations to operate as large organisations in large global markets. Linking up eBay and PayPal with UPS processes to enable purchases to be tracked during delivery. Managing all of the repair service processes for Toshiba in the US. A complete redesign of Ford Motors' distribution system in North America to reduce inventory holding reducing the inventory cycle from one month to ten days and improving the accuracy of orders/deliveries. 
As and when, commoditisation becomes significant a PRODUCT-SERVICE strategy based upon reverse (or frugal) innovation is pursued. The success of GE with its " $15 / 50$ " reverse innovation strategy in healthcare equipment represents a frugal approach; the product is re-designed to become functional and the service delivered is emphasised. A cautionary note; traditionalists may be resistant to a $15 / 50$ solution in some applications. While this may not be critical (to patient care as opposed to medical practitioners' incomes) it may have an impact that is of healthcare relevance and as such should be an important consideration in market information building.

\section{CONCLUDING COMMENTS: ARE THE CHARACTERISTICS OF THE ECONOMICS OF ORGANISATIONS CHANGING?}

Chandler's (1977) analysis of the development of industry in the USA identifies the role of the vertically integrated business of the early $20^{\text {th }}$ century and the emphasis on economies of scale. However Chandler did suggest that it was the economies of speed (the ability to coordinate the production sequences) were more critical for manufacturing efficiency. Subsequently economies of scope (these exist when the cost of jointly producing a range of products (or managing a process) within one organisation is less than the cost of producing the products separately across independent organisations: tangible and intangible aspects (e.g. manufacturing \& distribution and brands, R\&D and service)) shared importance with economies of scale in manufacturing.

\section{From Economics of the Organisation towards Economics of Networked Organisations}

The influence of network organisations has shifted the emphasis of the economics of production to the economics of added value, a collective term for responding to customer expectations for added value by the effective (strategic decision making) and efficient (operational management) of all of the value production operations:

Economies of scale: Create price advantages through 'managed' volume of production (Note: Economies of scope involve cost savings from joint production whereas economies of scale involve efficiencies from the production of higher volumes of a given product). Collaboration curves (Hagel et al, 2009) hold the potential to mobilize larger and more diverse groups of participants to innovate and create new value. In so doing they may also reverse the diminishing returns dynamics of the experience curve and deliver increasing returns to performance instead. (Hagel et al, 2009)

Economies of Scope: Exist when the cost of jointly producing a range of products (or managing a process) within one organisation is less than the cost of producing the products separately across independent organisations: tangible and intangible aspects (e.g. manufacturing \& 
distribution and brands, R\&D and service). They offer variety and choice through "product platform" design management

The Economics of Learning (experience effect): The unit cost of added value to a standard product declines by a constant percentage each time cumulative output doubles

Economies of Integration: Cost-effective management of overhead through strategic partnering. The principle of business integration; linking isolated activities into a single, integrated system that is fast, responsive, flexible and relatively low cost, resulting in a situation in which unit costs decrease as output increases because the activities of the entire operation are either increased by optimising and "leveraging" the ownership, distribution and location of assets throughout a value creation system., or that aggregate, investment and operating costs are decreased, or that perhaps both can be realised.

Economics of Coordination (Chandler's economies of speed): Optimise the costs of transformation, transactions and interactions throughout the value creation network (its fixed and variable cost structures) by establishing a strategy (and a structure) that ensures the tasks required for success are identified and planned, and that they are implemented and managed efficiently; coordination requires that the organisation "does the right things right - in time"!!

Economics of Interaction: The searching, coordinating and monitoring undertaken by organisations for effective and efficient means to exchange products, services and ideas. They occur on an intra-organisational basis as well as an inter-organisational basis. ICT developments continue to enhance the interactive capacity of industries and individual consumers such that it will create new ways to configure businesses, organisational structures and to service customers. Accordingly it will have a major impact on the strategy, structure and competitive dynamics of entire industries.

Economics of Motivation (to commit to network membership and membership continuity): Network structures the optimisation of resources management. Adam Smith suggested that markets are one very prominent mechanism for solving the problems that arise with the interdependencies of specialisation and division of labour. Smith was referring to end-user markets but the comment is applicable to resource markets within networks; a well-functioning network leads to" internalisation" as interdependence implies that one organisation's choices and actions have an impact on other network members but that it is end-user satisfaction that is the final arbiter and this is a major influence in the price mechanism within the network structure. 
The Economics of Transaction: Searching, coordinating and monitoring for effective and efficient means/media to exchange products, services and ideas that maximise added value during: developing specifications, searching/sourcing products \& services, evaluating alternatives, negotiating with suppliers, coordinating performance commitments, monitoring performance, and, supplier and customer relationship management.

The Economics of Relationships Management: Adding value by working with suppliers, intermediaries and end-user customers to identify cost-efficient value delivery alternatives using: collaboration through; co-productivity, co-opetition and co-creativity (prosumerism).

The Economics of Differentiation/Specialisation: Adding customer value by offering "product-service exclusivity" through customisation and "mass customisation" using specialisation, process and capability collaboration.

Economies of Time Response: Product and service customisation through DTO, BTO and QR operations process management.

The economics of complexity: the success of reverse innovation has identified the benefits of identifying the appropriate level of productservice sophistication on production costs and in market success.

The concept of network structures has expanded the nature of organisational economics from a limited perspective, based upon economies of scale (within which the firm became volume oriented striving to achieve its minimum cost/volume position on its long-run average cost curve (Chandler, 1962), and economies of scope (within which the firm attempts to reduce the fixed costs of both tangible and intangible assets by optimising utilisation); to a 'collective' perspective based upon a notion of dispersed operations (i e, the complete range of value creation, production, delivery and service provision). It is no longer sufficient to be the lowest cost provider in a market but rather it is now essential to be the most effective and efficient solution provider: end-user markets are product-service dominated. These may be PRODUCT-service markets, however in the New Economy many industrial markets are product-SERVICE markets: the customers are aware of product application performance but are often more influenced by service-maintenance availability rather low prices, hence the approach by major manufacturers of such products as aero-engines which are priced by the hour of serviceable use. 


\section{REFERENCES}

Agence-France (2010), 'Nissan to Move Production to Cut Currency Risk', Available from: www.IndustryWeek.com, 22 November.

Agence-France (2010a), "Toyota Unveils R\&D Unit in China', www.IndustryWeek.co, 17 November.

Allen, P. (2011), " Russia: Undervalued BRIC or Major Risk?" CNCB News, 17 May.

Anonymous (2010), "Japan's big companies are shipping production abroad", The Economist, 18 November.

Anonymous (2010), "Nissan Considers Bringing Electric Car Technology to China", Industry Week, Available from: www.industryweek.com, 20 September.

Anonymous (2010), "Nissan to Move Production to Cut Currency Risk", Financial Times, Available from: /www.industryweek.com, 22 November.

Anonymous Report (2010), "Nah, no", The Economist 13 November.

Anonymous Report (2010), "China, India Could Reshape Global Auto Industry", Industry Week, Available from: www.industryweek.com. 10 September.

Åslund, A. (2010), "Does Russia belong in the Brics?" Economists Forum, Financial Times, 20 January.

Barkai J. and Manenti P. (2011), “The Assembly Plant of the Future”, Industry Week, 12 January.

Boeing, (2011), Available from: www.Boeing.com/commercial/777family/pf/pf_ facts.html

Buss, D. (2007), "Winning with Global Value Chains", Chief Executive, March.

Chandler, A. (1962), Strategy and Structure: Chapters in the History of American Industrial Enterprise, MIT Press.

Chandler, A. (1997), The Invisible Hand: The Managerial Revolution in American Business, Harvard University Press, Cambridge, Mass.

Economist staff (2009), Japan's medium sized organisations - "chuken kigyos" Economist, 7 November.

Friedman, T. L. (2005), The World is Flat: the Globalized World in the Twenty First Century, Penguin Books, London.

Fung, F., Fung, W. \& Wind, Y. (2008), Competing in a Flat World, Wharton School/Pearson Education, NJ.

Gittings, R. (2011), "East moves west - and it's not just a miner miracle", Sydney Morning Herald, 28 May. 
Glynn, J. (2011), “Asian economic power to rival US in global markets soon”, Dow Jones Newswires in The Australian, 14 April.

Grey, B. (2006), Manufuture-EU, 2006.

Hagel, J. , Brown, J. S. \& Davison, L. (2009), "Introducing the Collaboration Curve", Harvard Business Review, 8 April.

Iansiti, M., Levien, R. (2004), "Strategy as ecology", Harvard Business Review (March), p. 68-78.

Immelt, J. \& Govindarajan, V. (2009), "How GE is Disrupting Itself”, Harvard Business Review, October.

infor White Paper (2006), Available from: www.infor.com.

Katz, J. (2010), "Bill Ford Sheds Light on Turnaround Success", IndustryWeek, 10 November.

Knowledge@Wharton (2011), “Manufacturing in a Two-speed World”, PARS International, 4 February.

Majocchi, L., Sacchi, A. \& Serio, L. (2010), "North American Manufacturers Missing Out on International Opportunities", Viewpoint: IndustryWeek, 16 November.

Manufuture (2006), Strategic research agenda, Retrieved from: http://www.manufuture.org/manufacturing/wp-content/uploads/Manufuture-

SRA-web-version.pdf

Myers J. (2006), IMS (Intelligent Manufacturing Systems), Vision Forum 2006

Piore, M., Sabel, C. F. (1984), The Second Industrial Divide: Possibilities for Prosperity, Basic Books, New York.

Schumpeter (2011), "Nipping at their heels", The Economist, 22 January (19962011),

Travel Document Systems Inc., (2011), "Brazil", NY, Retrieved from: http://www.traveldocs.com/

Uren D. (2001), "To winners go more spoils in rivalry tango," The Australian, 10 March.

Wakabayashi, D. (2009), "Panasonic downsizes product design and price to fit emerging markets", The Australia/Wall Street Journal, 10 July.

Walters S. (2010), Investment Analysis Report, J P Morgan, Sydney, Australia cited Winestock see Winestock (2010) below

Winestock G. (2010), "We're in box seat for Asia-led growth", Australian Financial Review, 5 January.

Rayport, J.F., Sviokla, J. J. (1994), Managing in the Marketspace, Harvard Business Review, November/December 1994 


\section{ABOUT THE AUTHOR}

David Walters, Institute of Transport and Logistics Studies, The University of Sydney, New South Wales, Australia.

email: david.walters@sydney.edu.au 